\title{
ВЗАИМОСВЯЗЬ ГОСУДАРСТВЕННОЙ ФИСКАЛЬНОЙ ПОЛИТИКИ С ДЕНЕЖНО-КРЕДИТНОЙ И ТАРИФНОЙ ПОЛИТИКОЙ В РОССИЙСКОЙ ФЕДЕРАЦИИ
}

\author{
(c) 2021 Андриеш Станислав Валерьевич \\ студент Финансового факультета \\ Финансовый университет при Правительстве Российской Федерации, Россия, Москва \\ E-mail: stas.andriesh@mail.ru
}

В рамках статьи была рассмотрена тема координации трёх основных политик, проводимых в Российской Федерации, которые являются составляющими финансовой политики (фискальная политика, денежно-кредитная политика и тарифная политика). Объектом работы выступает процесс реализации данных видов политик в Российской Федерации. Предметом является система координации фискальной политики с денежно-кредитной и тарифной политикой. В работе были применены такие методы исследования как: анализ, обобщение, сравнение. Выявлены основные проблемы реализации финансовой политики в Российской Федерации и предложены пути их решения. По итогам работы были сделаны определенные выводы. Описанные пути решения проблем в координации проведения соответствующих политик в России могут быть полезны публично правовым образованиям для улучшения возможности ориентироваться в экономических процессах, происходящих на уровне национальной экономики, а также для понимания смысла происходящих событий с целью грамотной корректировки экономического курса для достижения наивысшего уровня благосостояния населения.

Ключевые слова: фискальная политика, монетарная политика, таможенно-тарифная политика, координация, экономика, налоги, ставка, инфляция

\section{Введение и теоретические аспекты}

Ни одно государство в мире невозможно представить без его финансовой политики, ведь финансовая политика государства является необходимой составляющей всей его деятельности.

Если рассмотреть функции государства, то можно убедиться в том, что для их реализации присутствие финансового аспекта обязательно: обеспечение национальной безопасности, участие в решении глобальных проблем, обеспечение правопорядка и законности, регулирование экономических отношений - всё это требует денежных вложений. Финансовая политика, включающая в себя фискальную, таможеннотарифную, денежно-кредитную политики, одной из своих главных задач ставит обеспечение наибольшей эффективности использования денежных средств.

Актуальность темы исследования определяется прежде всего тем, что денежно-кредитная, фискальная и тарифная политики занимают ключевые положения в макроэкономическом регулировании. Их грамотное проведение обеспечивает успешное экономическое развитие государства и рост доверия к нему населения.
Именно поэтому крайне важно понимать каким образом политики взаимодействую друг с другом, и при каких условиях их координация может привести к наилучшему результату в вопросе экономического развития государства.

Целью работы является оценка эффективности проведения соответствующих политик в Российской Федерации. Для этого необходимо, во-первых, выявить особенности функционирования и изучить составляющие финансовой политики, во-вторых, рассмотреть проблемы реализации финансовой политики, в-третьих, проанализировать координацию фискальной, денежно-кредитной и таможенной политики.

Выдвигается гипотеза о том, что реализация фискальной политики, денежно-кредитной политики и таможенно-тарифной политики отдельно друг от друга не может способствовать такому же эффективному развитию экономических отношений между органами государственной власти и населением, как при их совместной координации.

Для формирования целостного представления об особенностях функционирования составляющих государственной финансовой политики 
в Российской Федерации, прежде всего стоит рассмотреть всю работу финансовой политики, которая является основой в процессе управления финансами общественного сектора.

Государственная финансовая политика - совокупность особых мер, которые разрабатываются уполномоченными органами государственной власти в области финансов для осуществления эффективной экономической и социальной политики государства. В соответствии с Конституцией РФ разработка государственной финансовой политики является полномочием Правительства Российской Федерации, а в его составе - Министерства финансов Российской Федерации.

Финансовая политика преследует определённые цели, которые ведут к развитию государства и общества, а именно - обеспечение уровня жизни населения, направление финансовых ресурсов в сторону приоритетных направлений, установление рационального режима использования национальных богатств и финансовое обеспечение эффективного государственного и муниципального управления. Достижение этих целей обеспечивается благодаря комплексному функционированию составляющих государственной финансовой политики.

Кроме всего вышесказанного, стоит отметить, что итоги проведения данной политики зависят от определённых факторов, к которым относятся: во-первых, научный подход в вопросе создания концепции государственной финансовой политики; во-вторых, проведение прогнозирования наступления последствий реализации запланированных мероприятий при определении главных направлений использования государственных финансов; в-третьих, учёт предыдущего опыта, полученного в процессе реализации государственной финансовой политики. Необходимо определение целевых ориентиров, а также учёт национальных, географических и иных факторов, чьё влияние на государственную финансовую политику значительно. В заключение комплексный подход при выработке и проведении рассматриваемой политики, а также учёт внутреннего положения и международных позиций государства, определяющих особенности его экономического раз- вития.

Как уже отмечалось выше, наиболее успешное достижение целей государственной финансовой политики возможно благодаря комплексной работе её составляющих - фискальной политике, денежно-кредитной и тарифной политик.

Фискальная политика представляет собой совокупность бюджетной и налоговой политики, при её применении происходит воздействие на экономику с помощью изменения величины расходов или доходов государственного бюджета. Основными инструментами данной политики являются налоги, трансферты и государственные закупки товаров и услуг.

Что касается денежно-кредитной политики, то она представляет собой действия государственных учреждений на денежном и валютном рынке. Эти действия направлены на контроль обменного курса, на уровень инфляции, занятости, стабильности экономического роста.

Тарифная политика - часть государственной финансовой политики, включающая совокупность тарифных мер, которые используются как национальное торгово-политический инструментарий для регулирования внешней торговли.

Проблемы реализации финансовой политики в РФ и пути их решения

Стоит отметить, что в процессе реализации финансовой политики наблюдаются определённые проблемы. Среди главных из них исследователи выделяют следующие*:

- Несогласованность бюджета различных уровней и внебюджетных фондов

- Отрицательные стороны налоговой системы

- Неудовлетворительные показатели в сфере финансирования инвестиций

- Волатильность национальной валюты

- Нерезультативное пользование государственной собственностью

В качестве приоритетного вопроса при дальнейшем прогнозировании экономического развития страны стоит вопрос об оптимальной координации фискальной, монетарной и тарифной политик в целях обеспечения приемлемого уровня удовлетворения потребностей населения и защиты имеющегося интеллектуального

\footnotetext{
* Курылева О.И., Курылев А.И., Давтян Л.К. Особенности разработки финансовой политики в компании, осуществляющей деятельность в сфере туризма В сборнике: Социальные и технические сервисы: проблемы и пути развития сборник статей по материалам II Всероссийской научно-практической конференции. Нижегородский государственный педагогический университет им. К. Минина. 2015. С. 402-405.
} 
потенциала и национального богатства страны. Основные проблемы финансовой политики можно решить с помощью достижения целей, определенных в таблице 1.
Стоит отдельно обратить внимание на устойчивость курса национальной валюты, которая может быть обеспечена за счет уменьшения спекуляции на рынке валют. К примеру, меры мо-

Таблица 1. Решения проблем финансовой политики в РФ

\begin{tabular}{|c|c|}
\hline Цели & Принимаемые меры \\
\hline $\begin{array}{l}\text { Согласованность } \\
\text { бюджета } \\
\text { различных } \\
\text { уровней } \\
\text { внебюджетных } \\
\text { фондов } \\
\text { государства }\end{array}$ & $\begin{array}{l}\text { 1. Повышение сбора налогов } \\
\text { 2. Уменьшение расходов } \\
\text { 3. Увеличение эмиссионных и неэмиссионных } \\
\text { ресурсов финансирования дефицита бюджета }\end{array}$ \\
\hline $\begin{array}{l}\text { Повышение } \\
\text { сбора налогов }\end{array}$ & $\begin{array}{l}\text { 1. Увеличение налогооблагаемой базы } \\
\text { 2. Снижение просроченных задолженностей } \\
\text { 3. ужесточение контроля за финансами } \\
\text { 4. преобразование схемы зачисления денежных } \\
\text { средств на уровни бюджетной системы }\end{array}$ \\
\hline $\begin{array}{l}\text { Увеличение } \\
\text { совокупного } \\
\text { предложения, как } \\
\text { гарант } \\
\text { финансирования } \\
\text { инвестиций }\end{array}$ & $\begin{array}{l}\text { 1. Привлечение внешних и внутренних займов } \\
\text { 2. Привлечение запасов граждан, имеющие } \\
\text { сверхвысокие доходы }\end{array}$ \\
\hline $\begin{array}{l}\text { Обеспечение } \\
\text { устойчивости } \\
\text { курса рубля }\end{array}$ & Уменьшение спекуляции на рынке валют. \\
\hline $\begin{array}{l}\text { Увеличение } \\
\text { результативности } \\
\text { бюджетного } \\
\text { сектора }\end{array}$ & $\begin{array}{l}\text { Преобразование системы } \\
\text { государственного сектора, то есть создание } \\
\text { устройств, которые будут обеспечивать устойчивое } \\
\text { приспособление зарплаты трудящихся к ситуации } \\
\text { рынка труда и оказывать важное стимулирующее } \\
\begin{array}{l}\text { влияние на бюджетный сектор в } \\
\text { производительности труда. }\end{array}\end{array}$ \\
\hline
\end{tabular}


нетарной политики направлены на сдерживание темпов роста инфляции путем побуждения населения к использованию иностранных валют в качестве основного типа сбережений. Данные меры негативно влияют на динамику курса национальной валюты по отношению к иностранным. Другими словами, такого рода вложения имеют спекулятивный характер. По итогу, государство создает условия для конвертации иностранных валют в активы национальной валюты, что, непосредственно, влияет на увеличение объема сбережений на счета коммерческих учреждений с целью сохранить вклады и получить от них пассивный доход.

Таким образом, приведенные меры могут обеспечить финансовой политике более устойчивое положение, оптимизировать процесс ее разработки. Несомненно, результаты проведения финансовой политики прямо зависят от того, как будут реализованы запланированные преобразования, как быстро органы власти будут принимать правильные решения в условиях постоянно меняющихся условий в экономике, а также от того, насколько четко и своевременно будут отражаться пути и факторы исполнения составляющих денежного механизма.

Координация фискальной, денежнокредитной и таможенной политики как основа для обеспечения долгосрочного экономического развития

Основной вопрос при реализации фискальной, денежно-кредитной и таможенной политик одновременно заключается в правильной их координации между собой. К примеру, фискальная политика ориентирована на средне-, долгосрочный эффект, в то время как денежно-кредитная политика имеет краткосрочный эффект. Если органы государственной власти больше ориентированы на проведение денежно-кредитной политики, то риск невозврата средств (в случае с помощью малому и среднему предпринимательству) намного выше, чем при ориентире на фискальную политику, которая этим вопросом почти не задается.

Темпы роста экономики напрямую зависят от изменения таких показателей, как объем реального ВВП, ВВП, рассчитанного по паритету покупательной способности на душу населения, доля инвестиция в ВВП.

Банк России признал, что одним из главных и решающих факторов, который оказывает наибольшее влияние на эффективность монетарного регулирования является проведение грамотной бюджетной политики в части ее предсказуемости, способности обеспечить достаточный уровень устойчивости экономических ожиданий.

Влияние фискальной политики на денежнокредитную можно рассматривать в двух сторон:

1. Влияние на инфляцию с помощью структуры, результативности и равномерности в течение финансового года бюджетных расходов

2. Снижение колебаний национальной валюты и сглаживание влияний изменений внешнеэкономической конъюнктуры на внутренние условия в рамках проведения бюджетных правил

Тем самым, изменяя ставки прямых и косвенных налогов, которые могут иметь инфляционный эффект, фискальная политика требует реакции со стороны денежно-кредитной политики.

Для поддержания устойчивого уровня покупательской способности необходимо направить инструменты фискальной политики на увеличение объемов производства, которое будет обеспечено увеличением денег в обращении. Спрос на финансовом рынке зависит от объема государственных закупок. Поэтому, если центральный банк не обеспечивает устойчивый и сбалансированный рост денежной массы в обращении, могут вырасти цены и процентные ставки. Следовательно, в следствие уменьшения спроса на товары, результативность бюджетно-налоговой политики становится минимальной.

В качестве основной задачи координации фискальной и денежно-кредитной политики служит оптимизация государственного долга и темпов развития инфляции. В основе этого вопроса расположились два соображения:

1. Центральный банк и правительство объединяются консолидированным бюджетным ограничением общественного сектора.

Источники финансирования дефицита формируются за счет государственных заимствований и дохода от эмиссии денежной базы (сеньораж), объем которой определяется действиями центрального банка на открытом рынке. Иначе говоря, монетарная политика обозначает состав государственного долга путем обмена государственных облигаций на денежную базу в то время, как фискальная политика определяет уровень объема государственных заимствований. Тем самым, центральный банк берет на себя часть бремени по финансированию дефицита 
бюджета.

2. Вопросы о стабильности денежного рынка и регулировании темпов роста инфляции рассматриваются в приоритете как правительством, так и центральным банком.

Это означает, что правительство и центральный банк, проводя свои политики будь то совместно или автономно, преследуют общие цели и вынуждены взаимодействовать друг с другом в той или иной форме.

При изучении сложной взаимосвязи фискальной и денежно-кредитной политик можно выделить две основные проблемы:

1. Есть риск существование более одного уровня инфляции, для которых денежный рынок и бюджетно-налоговая сфера находятся в неизменном состоянии.

В таком случае, в зависимости от того, на каком равновесии находится экономика, последствия на денежном рынке сильно зависят от изменений в бюджетно-налоговой сфере и, наоборот, последствия изменения в монетарной политике влияют на последствия в фискальной политике.

2. Реальные эффекты инфляции.

В зависимости от ряда случаев объем бюджетного дефицита может как увеличиваться, так и уменьшаться по мере роста уровня инфляции. При этом, снижение бюджетного дефицита предполагает совершенно иной набор равновесий по сравнению с ситуацией, когда бюджетный дефицит рассматривается, как экзогенная величина.

Касаемо таможенной политики, она направлена на увеличение неналоговых доходов федерального бюджета, а именно - сборов таможенных пошлин и сборов, которые зачисляются в бюджет по нормативу 100\%, и она тесно связана с налоговой и ценовой политикой. Как результат таможенные пошлины в укрупненной группе доходов федерального бюджета РФ «ДОХОДЫ ОТ ВНЕШНЕЭКОНОМИЧЕСКОЙ ДЕЯТЕЛЬНОСТИ» занимают около 80\% за период 2017-2021 гг., следовательно, около 14,5\% от всех доходов федерального бюджета РФ. Это нам говорит о том, что данная статья доходов является одной из ключевых в формировании денежных поступлений государства и правильная координация проведения фискальной и таможенной политик должна быть в списке приоритетных направлений при реализации соответствующих политик органами государственной власти.
Тем самым, реализация таможенной политики определяет рост доли налогов и сборов на внешнеэкономические операции в структуре доходов федерального бюджета.

В экономической истории Российской Федерации прописано множество случаев удачной координации фискальной и денежно-кредитной политик. Наиболее ярким примером может послужить валютный кризис в России в 2014 году, который был обусловлен резким спадом российского рубля к иностранным валютам. В целом, этот спад объясняется снижением мировых цен на нефть, формировавшие основную часть денежных поступлений в федеральный бюджет. Уже на начально этапе проявления кризиса проявилось снижение темпов экономического развития и потребительского совокупного спроса, а также был отмечен рост бедности населения и уровня инфляции.

Стоит разобрать, как были реализованы фискальная и монетарная политики, проводимые Правительством РФ и Центральным банком России соответственно, в кризисном периоде. Меры по стабилизации экономической ситуации принимались совместно:

- Со стороны проведения денежно-кредитной политики.

Ключевую ставку поднимали 6 раз в 2014 году, чтобы удержать рост инфляции, и 5 раз снижали в 2015 году, чтобы создать благоприятные условия для экономической стабилизации.

- Со стороны проведения фискальной политики.

Смягчение условий резервирования для банков, которые реструктурируют валютные ипотечные кредиты с целью помощи заемщикам, попавший в непростое экономическое положение. Также были предприняты меры по регулированию деятельности спекулянтов, которые играли на колебаниях российского рубля и установлению лимитов валютных активов крупных компаний-экспортеров, которые предписывали снижение уровня запасов национальной валюты при предоставлении государственный гарантии с целью обеспечение экономической стабилизации валютного рынка.

Рассмотрим еще один пример из истории российской экономики, который демонстрирует как при отсутствии грамотной координации составляющих финансовой политики возникает кризисная ситуация. В 1995-1998 годах при ведении экономической политики, государством 
были допущены серьёзные ошибки. В конце 1994 года российское правительство прекратило практику финансирования госбюджета за счёт эмиссии. В это же время Центробанк начал придерживаться политики «валютного коридора», при котором происходило удержание курса российского рубля к доллару США с помощью валютных интервенций. Финансирование бюджетного дефицита происходило по большей части за счёт заимствований на финансовых рынках. Фискальная политика была построена таким образом, что основная часть расходов федерального бюджета была направлена на рефинансирование ценных бумаг. Реализация такого подхода значительно ограничивала возможности органов государственный власти в поддержке экономического развития, а также социальной сферы. Также стоит отметить, что увеличение государственного долга провоцировало увеличение рисков, которые могут изменять стоимость долга из-за колебаний ценных бумаг и национальной валюты.

Важно отметить, что ужесточение денежнокредитной политики, в условиях политической борьбы, которая происходила в тот момент времени, не было поддержано действиями Правительства РФ. Принимаемые Государственной Думой меры были определены сильнейшей на тот момент фракцией, КПРФ, которая, в качестве своих убеждений, стремилась увеличивать государственные расходы, одновременно принимая несбалансированные бюджеты, в которых затраты не обеспечивались поступлениями. В следствие этого, органы государственной власти пытались разрешить противоречия путем увеличения объема государственного долга.

В результате, отсутствие грамотной координации фискальной и денежно-кредитной политик привело к кризису 1998 года, который признаётся одним из самых тяжёлых в истории России.

\section{Заключение}

В качестве определяющего фактора, показывающий уровень экономического развития и устойчивости национальной экономики, служит решение проблем координации фискальной и денежно-кредитной политик, проводимые правительством и центральным банком соответственно.

Одним из основных направлений анализа экономической устойчивости национальной экономики является решение проблемы взаимо- действия правительства и центрального банка, проводящие фискальную и денежно-кредитную политику соответственно.

По итогу проделанной работы был проведен анализ проведения и координации трёх составляющих финансовой политики Российской Федерации: фискальной, денежно-кредитной и тарифной политик. Также были выявлены недостатки реализации финансовой политики, на основе которых предоставлены пути их устранения.

Говоря о координации фискальной и монетарной политик, стоит отметить, что проведение соответствующих политик правительством и центральным банком пересекаются консолидированным бюджетным ограничением государственных финансов (За счет сеньоража центральный банк выступает в качестве одного из источников финансирования бюджетного дефицита), в то время, как контроль и регулирования уровня инфляции должен быть в качестве приоритетных задач как у правительства, так и у центрального банка.

В случае, когда дефицит бюджета снижается по мере роста уровня инфляции, скоординированная политика центрального банка и правительства, направленная на минимизацию рисков возникновения кризисных ситуаций, существенно меняет свои принципы построения.

На начальном этапе написания работы была выдвинута гипотеза о том, что автономная и самостоятельная реализация фискальной политики, денежно-кредитной политики и таможеннотарифной политики, проводимые в Российской Федерации, не может способствовать здоровому развитию экономических отношений между органами государственной власти и населением, поддерживая при этом высокий уровень ее доверия. Гипотеза подтвердилась историческими фактами, а именно кризисами, возникшие в Российской Федерации в 1998 и 2014 годах, как наиболее ярко отражающие основные аспекты и идеи данной статьи.

Данная статья может быть полезна публично правовым образованиям для улучшения возможности ориентироваться в экономических процессах, происходящих на уровне национальной экономики, а также для понимания смысла происходящих событий с целью грамотной корректировки экономического курса для достижения наивысшего уровня благосостояния населения. 


\section{Библиографический список}

1. «Бюджетный кодекс Российской Федерации» от 31.07.1998 N 145-Ф3 (ред. от 22.12.2020) (с изм. и доп., вступ. в силу с 01.01.2021)

2. Федеральный закон № 39-Ф3 от 25.02.1999 «Об инвестиционной деятельности в Российской Федерации, осуществляемой в форме капитальных вложений»

3. Федеральный закон № 395-1 «О банках и банковской деятельности» от 02.12.1990

4. Федеральный закон № 86-Ф3 «О Центральном банке РФ (Банке России)» от 27.06.2002.

5. Указ Президента РФ от 21.07.2020 № 474 «О НАЦИОНАЛЬНЫХ ЦЕЛЯХ РАЗВИТИЯ РОССИЙСКОЙ ФЕДЕРАЦИИ НА ПЕРИОД ДО 2030 ГОДА»

6. «Основные направления бюджетной, налоговой и таможенно-тарифной политики на 2021 год и на плановый период 2022 и 2023 годов» (утв. Минфином России)

7. «Основные направления единой государственной денежно-кредитной политики на 2021 год и период 2022 и 2023 годов» (утв. Банком России)

8. Алиева Ж.М., К.Х.Ильясова, Я.Сайд-Хусейновна Джумаева, М.М.Эскиева СОВРЕМЕННАЯ ФИНАНСОВАЯ ПОЛИТИКА РОССИЙСКОЙ ФЕДЕРАЦИИ // ЕГИ. 2020. № 5 (31). URL: https://cyberleninka.ru/article/n/ sovremennaya-finansovaya-politika-rossiyskoy-federatsii.

9. Афанасьев М. Модернизация государственных финансов/ М. Афанасьев.- Москва: Гостехиздат, 2016. - $181 \mathrm{c}$

10. Гаспар В., Люк Эйро «Пять ключевых факторов разумной налогово-бюджетной политики» / IMFBlog / INSIGHTS AND ANALYSIS ON ECONOMICS \& FINANCE. 2017 г.

11. Захарян А. В. Финансовая политика России на современном этапе - / Захарян А. В., Неводова И. А., Кумпилов Н. Т., Назаретян К.А., Сальков Д. А. // Экономика и предпринимательство. 2018. № 11(100). С.145-148

12. Курылева О.И., Курылев А. И., Давтян Л. К. Особенности разработки финансовой политики в компании, осуществляющей деятельность в сфере туризма В сборнике: Социальные и технические сервисы: проблемы и пути развития сборник статей по материалам II Всероссийской научно-практической конференции. Нижегородский государственный педагогический университет им. К. Минина. 2015. С. 402-405.

13. Abiad A., D. Furceri, and P. Topalova (2015), The Macroeconomic Effects of Public Investment: Evidence from Advanced Economies, IMF Working Paper 